\title{
Purification, crystallization and X-ray crystallographic analysis of RPTPH
}

\author{
Myeongbin Kim and Seong Eon Ryu* \\ Department of Bioengineering, College of Engineering, Hanyang University, Seoul 04763, Republic of Korea \\ ${ }^{*}$ Correspondence: ryuse@hanyang.ac.kr
}

Receptor-type protein tyrosine phosphatases (RPTPs) belong to the protein tyrosine phosphatase (PTP) family and play a critical role in cell signaling. RPTPH, a type of RPTP, consists of long extracellular domains, a transmembrane domain, and a single intracellular domain with phosphatase activity. RPTPH is involved in phosphorylation of target proteins involved in the AKT signaling pathway and regulates T-cell function and cell apoptosis. The protein is also implicated in progression of colorectal and lung cancers. Despite the importance of RPTPH in tumor-related cell signaling and therapeutic drug development, the structure of this enzyme has not yet been determined. We overexpressed, purified, and crystallized the catalytic domain of RPTPH. The RPTPH crystal diffracted at a resolution of $1.56 \AA$. It belonged to the space group P $3_{2}$ with unit cell parameters $a=b=56.46 \AA, c=80.45 \AA, \alpha=\beta=90^{\circ}$, and $\gamma=120^{\circ}$.

\section{INTRODUCTION}

Protein tyrosine phosphatases (PTPs) dephosphorylate phosphotyrosine and phosphothreonine residues on target proteins. These enzymes play a critical role in cell signaling and are associated with cell proliferation, apoptosis, and survival (Tonks, 2006). Receptor-type PTPs (RPTPs), a subfamily of PTPs, are membrane-bound phosphatases, consisting of a transmembrane domain, extracellular domains, and intracellular catalytic domains. The extracellular regions of RPTPs have variable forms with combination of repeated fibronectin type III (FN3) domains, an $\alpha$-carbonic anhydrase domain, and immunoglobulin-like domains. These regions interact with diverse ligands such as adhesion proteins, and proteoglycans, and control the oligomerization of RPTPs to affect enzyme activity (Coles et al., 2011; Mohebiany et al., 2013). The intracellular regions of RPTPs are composed of one or two catalytic domains with a canonical PTP fold comprising a central $\beta$-sheet surrounded by $\alpha$-helices. The catalytic cysteine resides in the shallow pocket formed by the P-loop at one side of the PTP-fold. The active site cysteine plays as an electrophile and prone to oxidation. These catalytic domains dephosphorylate substrates or interact with target proteins to regulate cell signaling (Tonks, 2006). RPTP regulation is involved in various signaling pathways associated with diseases such as cancers, neurological disorders, and rheumatoid arthritis (Nikolaienko et al., 2012; Doody et al., 2015; Ohtake et al., 2018). Therefore, RPTPs are regarded as a promising drug target, and efforts to develop such drugs are ongoing (Xu and Fisher, 2012; Zhang et al., 2019).

RPTPH, or stomach cancer-associated protein tyrosine phosphatase 1 (SAP1), is an RPTP with extracellular FN3 domains and a single intracellular catalytic domain. The latter has the signature HCX5R motif in the active site, as other PTPs do, showing a phosphatase activity. Several studies have shown that RPTPH directly regulates the phosphorylation level of tyrosine protein kinases involved in the AKT signaling pathway, regulating $\mathrm{T}$-cell function and cell apoptosis (Takada et al., 2002; Ito et al., 2003). Colorectal, and lung cancers also implicate RPTPH (Seo et al., 1997; Sato et al., 2015). Structural studies on the catalytic domains of PTPs provided insightful information on their therapeutic potential (Zhang, 2017). However, the structural features of RPTPH have not yet been elucidated. Here, we report the crystallization of the RPTPH catalytic domain for structure determination at an atomic resolution.

\section{RESULTS AND DISCUSSION}

The oligonucleotide encoding the RPTPH catalytic domain was amplified and cloned into the pET28a expression plasmid of Escherichia coli. The HRV-3C protease recognition site was added to the gene using polymerase chain reaction (PCR). The recombinant protein was expressed in Escherichia coli BL21 (DE3) and purified by nickel affinity chromatography and gel filtration chromatography. The $\mathrm{N}$-terminal tag for affinity chromatography was cleaved by HRV-3C protease. Because the wild-type RPTPH catalytic domain was unstable, the active site cysteine (C1020) and the surface-exposed cysteine (C818) were mutated to serine and alanine, respectively (C1020S and C818A). The active site cysteine is prone to oxidation and often mutated to serine in previous PTP structures. The position and characteristics of these residues were predicted by sequence alignment with a receptor-type PTP RPTPJ of which structures have been determined previously (PDB ID: 2CFV and 2NZ6). The mutant protein showed improved stability when purified using the same procedure as the wild-type protein. SDS-PAGE analysis showed that the protein had a high purity (Figure 1). The RPTPH sample was concentrated to $20 \mathrm{mg} / \mathrm{ml}$ for crystallization. Initial crystallization was conducted by using commercial kits. 
Crystals were obtained within 2 days from a solution containing $0.1 \mathrm{M}$ MES-NaOH pH 6.5 and 13\% (v/v) polyethylene glycol monomethyl ether (PEGMME) 550. The crystals were confirmed to be protein by staining with Izit dye. The crystal used for data collection appeared in a 2:1 mixture of protein and reservoir solutions (Figure 2). Data collection was conducted at beamline 7A at Pohang Accelerator Laboratory (Park et al., 2017). The crystal was soaked in a cryo-protectant solution [0.1 M MES$\mathrm{NaOH} \mathrm{pH} 6.5,40 \%$ (v/v) PEGMME 550, and 10\% glycerol] for 10 seconds for cryo-protection, then loaded onto a nylon loop of $0.05-0.1 \mathrm{~mm}$ size. The RPTPH crystal diffracted to a resolution of $1.56 \AA$, belonging to the space group $\mathrm{P} 3_{2}$ with unit cell parameters $\mathrm{a}=\mathrm{b}=56.46 \AA \mathrm{c}, \mathrm{c}=80.45 \AA$, $\alpha=\beta=90^{\circ}, \gamma=120^{\circ}$ (Figure 3). The solvent content of the crystal was calculated to be $45.6 \%$ with Matthew's coefficient of $2.26 \AA^{3} / \mathrm{Da}$, indicating that the asymmetric unit contained a single molecule of RPTPH.

To conduct a molecular replacement (MR) process, the initial search model was prepared by the program Sculptor in Phenix (Liebschner et al., 2019). The crystal structure of RPTPJ catalytic domain (PDB entry 2NZ6) with sequence identity $47.9 \%$ was selected as an input model. The software Phaser was used

(A)

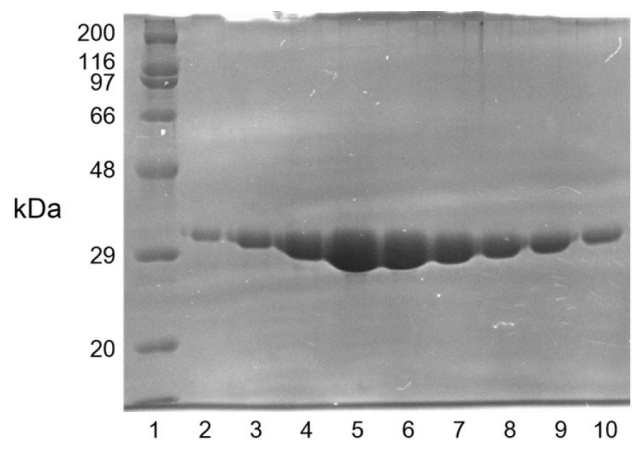

(B)

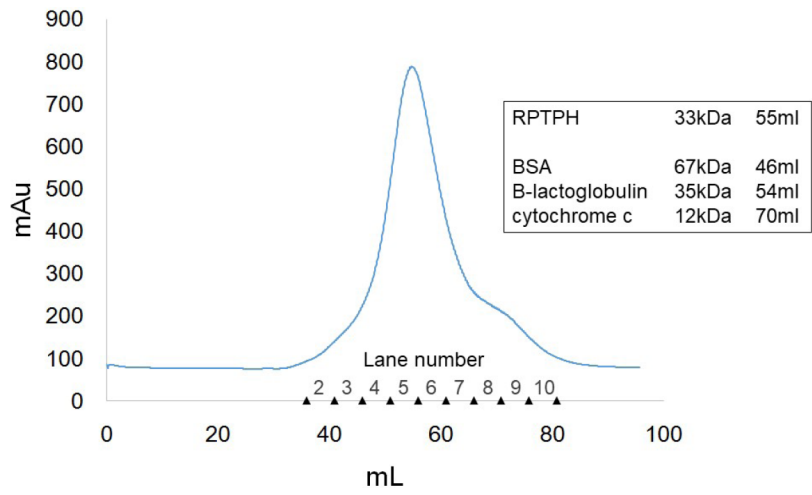

FIGURE 1 I Purified RPTPH catalytic domain protein on SDSpolyacrylamide gel. (A) The first lane is the molecular weight marker, and the other lanes (2-10) are the elution fractions of size exclusion chromatography. (B) The size exclusion chromatography profile of RPTPH purification. Samples of lane 2-10 in (a) are indicated above the $\mathrm{X}$-axis. $\mathrm{X}$ and $\mathrm{Y}$-axis represent elution volume and absorption unit, respectively (inset: elution peak volumes of RPTPH and standard proteins). to solve the structure from the prepared model with sufficient scores (TFZ = 30.9, and LLG = 914.5) (McCoy et al., 2007). The initial refinement of MR solution resulted in the values of R-work/ $\mathrm{R}$-free of $32.8 \%$ and $35.6 \%$, respectively. Further refinement and manual model building were performed to obtain a high quality crystal structure of RPTPH. The current R-work/R-free values are $17.8 \%$ and $20.7 \%$, respectively.

\section{METHODS}

\section{Protein expression}

The gene encoding human RPTPH (residues 798-1086; Uniprot Q9HD43-1) was amplified using PCR, and HRV-3C protease and restriction enzyme recognition sequences were inserted. The PCR product and pET28a plasmid DNA were digested by Ndel and Xhol restriction enzymes (New England Biolabs) and purified by agarose gel extraction. These nucleotides were ligated at room temperature for an hour by T4 DNA ligase (Enzynomics). Two mutations for cysteine residues were introduced using the Quikchange mutagenesis (Stratagene) protocol. The nucleotide sequences were confirmed using a DNA sequencing service

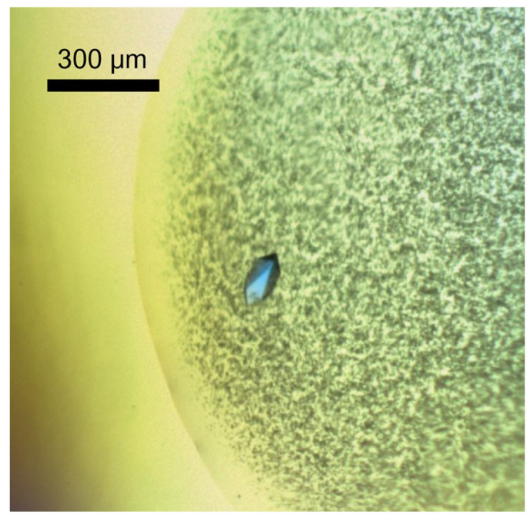

FIGURE 2 I A crystal of the RPTPH catalytic domain protein. The approximate dimension of the crystal is $0.20 \times 0.08 \times 0.08 \mathrm{~mm}$.

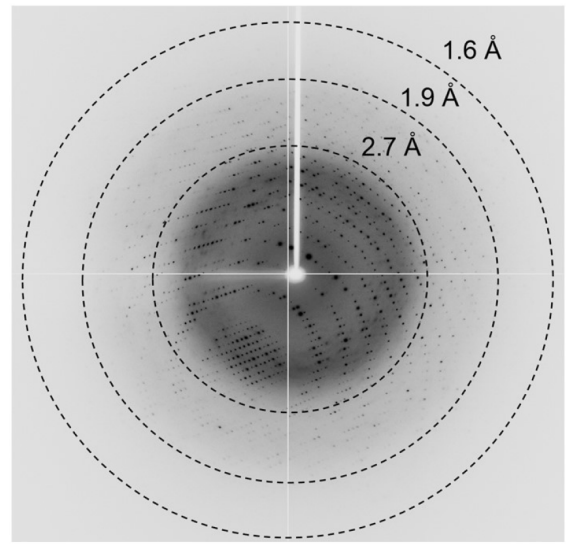

FIGURE 3 I Representative X-ray diffraction image of the RPTPH crystal. Three dashed lines represent resolution ranges of $2.7 \AA, 1.9 \AA$, and $1.6 \AA$. 
(Bionics). Table 1 presents the primer sequences used to manipulate the DNA.

\section{Purification of the recombinant protein}

Escherichia coli BL21(DE3) cells were transformed with the pET28a expression vector encoding the recombinant protein. Cells were cultured at $37^{\circ} \mathrm{C}$ in LB medium with $30 \mu \mathrm{g} / \mathrm{ml}$ kanamycin until $\mathrm{OD}_{600}$ reached 0.6 . To induce protein overexpression, isopropyl $\beta$-D-1-thiogalactopyranoside with a final concentration of $0.1 \mathrm{mM}$ was added to the culture medium. Cells were further incubated at $18^{\circ} \mathrm{C}$ for 16 hours and then harvested by centrifugation. The pellets were resuspended and disrupted by sonication in a lysis buffer (40 mM Tris- $\mathrm{HCl} \mathrm{pH}$ 7.5, $500 \mathrm{mM}$ $\mathrm{NaCl}$, and $7 \mathrm{mM}$ 2-mercaptoethanol). The soluble fraction of the lysate was separated by high-speed centrifugation and applied to a column filled with nickel affinity chromatography resin (Qiagen). Subsequently, the resin was washed with a wash buffer (40 $\mathrm{mM}$ Tris- $\mathrm{HCl} \mathrm{pH} \mathrm{7.5,} 500 \mathrm{mM} \mathrm{NaCl}$, and $30 \mathrm{mM}$ imidazole). The recombinant protein was eluted with a buffer containing $500 \mathrm{mM}$ imidazole, and this was followed by a buffer exchange $(20 \mathrm{mM}$ Tris- $\mathrm{HCl} \mathrm{pH} \mathrm{7.5,} 150 \mathrm{mM} \mathrm{NaCl}$, and $5 \mathrm{mM}$ 2-mercaptoethanol). The $\mathrm{N}$-terminal hexa-histidine tag was cleaved by HRV-3C protease at $4^{\circ} \mathrm{C}$ for 18 hours. After cleavage, the protein solution was applied to a nickel affinity chromatography resin to eliminate uncleaved proteins. The protein was further purified using a

TABLE 1 I Protein production

\begin{tabular}{|c|c|}
\hline Source organism & Homo sapiens \\
\hline $\begin{array}{l}\text { Forward primer for } \\
\text { cloning }\end{array}$ & $\begin{array}{l}\text { GGCCCATATGCTGGAAGTTCTGTTCCAGGGACC } \\
\text { TGGAGATATACCC }\end{array}$ \\
\hline $\begin{array}{l}\text { Reverse primer for } \\
\text { cloning }\end{array}$ & GGCCCTCGAGTTATGCTTGCGCAGA \\
\hline $\begin{array}{l}\text { Forward primer for } \\
\text { mutagenesis (C818A) }\end{array}$ & GAACGTGATAGCAACGCCGGTITTGCTGACGAA \\
\hline $\begin{array}{l}\text { Reverse primer for } \\
\text { mutagenesis (C818A) }\end{array}$ & TTCGTCAGCAAAACCGGCGTTGCTATCACGTTC \\
\hline $\begin{array}{l}\text { Forward primer } \\
\text { for mutagenesis } \\
\text { (C1020S) }\end{array}$ & CGCCTATTGTTCACTCCTCTGCCGGTGTGGG \\
\hline $\begin{array}{l}\text { Reverse primer } \\
\text { for mutagenesis } \\
\text { (C1020S) }\end{array}$ & CCCACACCGGCAGAGGAGTGAACAATAGGCG \\
\hline Expression vector & pET28a \\
\hline Expression host & E. coli BL21 (DE3) \\
\hline $\begin{array}{l}\text { Complete amino } \\
\text { acid sequence of the } \\
\text { construct produced }\end{array}$ & $\begin{array}{l}\text { MGSSHHHHHHSSGLVPRGSHMLEVLFQGPGDIP } \\
\text { AEDFADHVRKNERDSNAGFADEYQQLSLVGHSQ } \\
\text { SQMVASASENNAKNRYRNVLPYDWSRVPLKPIH } \\
\text { EEPGSDYINASFMPGLWSPQEFIATQGPLPQTVG } \\
\text { DFWRLVWEQQSHTLVMLTNCMEAGRVKCEHYW } \\
\text { PLDSQPCTHGHLRVTLVGEEVMENWTVRELLLLQ } \\
\text { VEEQKTLSVRQFHYQAWPDHGVPSSPDTLLAFW } \\
\text { RMLRQWLDQTMEGGPPIVHSSAGVGRTGIAL } \\
\text { DVLLRQLQSEGLLGPFSFVRKMRESRPLMVQTE } \\
\text { AQYVFLHQCILRFLQQSAQA }\end{array}$ \\
\hline
\end{tabular}

The underlined nucleotide sequences are for restriction enzyme recognition site. The underlined residues are a hexa-histidine tag and protease recognition site.
Sephacryl S-100 gel filtration chromatography column (Cytiva) equilibrated with a gel filtration chromatography buffer $(20 \mathrm{mM}$ Tris- $\mathrm{HCl} \mathrm{pH} \mathrm{7.5,} 150 \mathrm{mM} \mathrm{NaCl}$, and $2 \mathrm{mM}$ dithiothreitol). The protein was concentrated to $20 \mathrm{mg} / \mathrm{ml}$ and stored at $-70^{\circ} \mathrm{C}$. Table 1 shows the protein production information.

\section{Crystallization}

Crystallization was performed at $291 \mathrm{~K}$ using the sitting-drop vapor-diffusion method. Initial crystallization was conducted by mixing equal volumes of protein and reservoir solutions from commercial kits with the liquid handling system Mosquito (STP Labtech). The crystallization drops were incubated in a 96-well crystallization plate sealed with clear sealing tape. The initial crystal appeared after 2 days. Staining with Izit dye (Hampton Research) was performed to confirm whether the crystals were

TABLE 2 I Crystallization

\begin{tabular}{ll}
\hline Method & Sitting-drop vapor-diffusion \\
\hline Plate & $\begin{array}{l}\text { 96-well 2-drop MRC crystallization } \\
\text { plates (Swissci) }\end{array}$ \\
\hline Temperature & $18^{\circ} \mathrm{C}$ \\
\hline Protein concentration & $20 \mathrm{mg} / \mathrm{ml}$ \\
\hline Composition of protein solution & $\begin{array}{l}20 \mathrm{mM} \mathrm{Tris-HCl,} \mathrm{pH} 7.5,150 \mathrm{mM} \mathrm{NaCl}, \\
\text { and } 2 \mathrm{mM} \text { dithiothreitol }\end{array}$ \\
\hline Composition of reservoir solution & $\begin{array}{l}0.1 \mathrm{M} \mathrm{MES}-\mathrm{NaOH} \mathrm{pH} 6.5,13 \%(\mathrm{~V} / \mathrm{V}) \\
\mathrm{PEGMME} 550\end{array}$ \\
\hline Volume and ratio of drop & $\begin{array}{l}0.8 \mu \mathrm{l} \text { protein solution and } \\
0.4 \mu \mathrm{l} \text { reservoir solution }(2: 1)\end{array}$ \\
\hline Volume of reservoir & $70 \mu \mathrm{l}$ \\
\hline
\end{tabular}

TABLE 3 I Data collection statistics

\begin{tabular}{|c|c|}
\hline Diffraction source & Beamline 7A, PAL \\
\hline Wavelength $(\AA)$ & 0.97933 \\
\hline Temperature (K) & 100 \\
\hline Crystal-detector distance $(\mathrm{mm})$ & 180 \\
\hline Rotation range per image $\left(^{\circ}\right)$ & 1 \\
\hline Total rotation range $\left(^{\circ}\right)$ & 180 \\
\hline Exposure time per image (sec) & 0.5 \\
\hline Space group & $\mathrm{P}_{2}$ \\
\hline$a, b, c(\AA)$ & $56.46,56.46,80.45$ \\
\hline$\alpha, \beta, \gamma\left(^{\circ}\right)$ & $90.00,90.00,120.00$ \\
\hline Resolution range $(\AA ̊)$ & $24.45-1.56(1.62-1.56)^{\star}$ \\
\hline Total number of reflection & 149080 \\
\hline Number of unique reflection & 38471 \\
\hline Completeness (\%) & $94.2(87.7)$ \\
\hline $\mathrm{R}_{\text {merge }}(\%)$ & $6.9(31.7)$ \\
\hline$|/ \sigma|$ & $10.6(2.9)$ \\
\hline $\mathrm{CC}_{1 / 2}$ & $0.997(0.389)$ \\
\hline Redundancy & $3.9(2.5)$ \\
\hline
\end{tabular}

${ }^{*}$ The values in the parenthesis are for the highest resolution shell. 
protein molecules or inorganic compounds. The crystal used for data collection appeared and grew in drops containing a 2:1 ratio of protein solution and reservoir solution (0.1 M MES-NaOH pH 6.5, 13\% (v/v) PEGMME 550). Table 2 presents detailed information on the crystallization process.

\section{Data collection and processing}

X-ray crystallographic data were collected on beamline 7A at Pohang Accelerator Laboratory. Prior to diffraction, the crystal was transferred into $1.0 \mu \mathrm{l}$ of cryoprotectant solution (0.1 M MES-NaOH pH 6.5, 40\% (v/v) PEGMME 550, and 10\% glycerol) and flash-frozen in a nitrogen stream at $100 \mathrm{~K}$. Datasets were collected by rotating the crystal with an exposure time of 0.5 seconds per frame of one degree. The program HKL2000 was used to process, merge, and scale the diffraction datasets (Otwinowski and Minor, 1997). The MR solution was obtained using the crystal structure of RPTPJ (PDB entry 2NZ6) as an initial model and the programs Xtriage, Scultor, Phaser, and phenix.refine in Phenix suite were used for the structure determination (Liebschner et al., 2019). Table 3 shows the data collection statistics.

\section{ACKNOWLEDGEMENTS}

We thank the staff members of beamline 7A at the Pohang Accelerator Laboratory (PAL) for diffraction data collection. This work was supported by the biomedical technology development projects, National Research Foundation, KOREA [NRF2015M3A9B5030302 and NRF-2021M3A9G8024747].

\section{CONFLICT OF INTEREST}

The authors declare that they have no conflict of interest.

Original Submission: Aug 17, 2021

Revised Version Received: Sep 14, 2021

Accepted: Sep 14, 2021

\section{REFERENCES}

Coles, C.H., Shen, Y., Tenney, A.P., Siebold, C., Sutton, G.C., Lu, W., Gallagher, J.T., Jones, E.Y., Flanagan, J.G., and Aricescu, A.R. (2011). Proteoglycan-specific molecular switch for RPTP $\sigma$ clustering and neuronal extension. Science 332, 484-488.

Doody, K.M., Stanford, S.M., Sacchetti, C., Svensson, M.N., Coles, C.H., Mitakidis, N., Kiosses, W.B., Bartok, B., Fos, C., Cory, E., Sah, R.L., LiuBryan, R., Boyle, D.L., Arnett, H.A., Mustelin, T., et al. (2015). Targeting phosphatase-dependent proteoglycan switch for rheumatoid arthritis therapy. Sci Transl Med 7, 288ra276.

Ito, T., Okazawa, H., Maruyama, K., Tomizawa, K., Motegi, S., Ohnishi, H., Kuwano, H., Kosugi, A., and Matozaki, T. (2003). Interaction of SAP1, a transmembrane-type protein-tyrosine phosphatase, with the tyrosine kinase Lck. Roles in regulation of T cell function. J Biol Chem 278, 3485434863.

Liebschner, D., Afonine, P.V., Baker, M.L., Bunkóczi, G., Chen, V.B., Croll, T.I., Hintze, B., Hung, L.W., Jain, S., McCoy, A.J., Moriarty, N.W., Oeffner, R.D., Poon, B.K., Prisant, M.G., Read, R.J., et al. (2019). Macromolecular structure determination using $X$-rays, neutrons and electrons: recent developments in Phenix. Acta Crystallogr D Struct Biol 75, 861-877.

McCoy, A.J., Grosse-Kunstleve, R.W., Adams, P.D., Winn, M.D., Storoni, L.C., and Read, R.J. (2007). Phaser crystallographic software. J Appl Crystallogr 40, 658-674.

Mohebiany, A.N., Nikolaienko, R.M., Bouyain, S., and Harroch, S. (2013). Receptor-type tyrosine phosphatase ligands: looking for the needle in the haystack. FEBS J 280, 388-400.

Nikolaienko, R.M., Agyekum, B., and Bouyain, S. (2012). Receptor protein tyrosine phosphatases and cancer: new insights from structural biology. Cell Adh Migr 6, 356-364.

Ohtake, Y., Saito, A., and Li, S. (2018). Diverse functions of protein tyrosine phosphatase $\sigma$ in the nervous and immune systems. Exp Neurol 302, 196-204.

Otwinowski, Z., and Minor, W. (1997). Processing of X-ray diffraction data collected in oscillation mode. Methods Enzymol 276, 307-326.

Park, S.Y., Ha, S.C., and Kim, Y.G. (2017). The protein crystallography beamlines at the Pohang Light Source II. Biodesign 5, 30-34.

Sato, T., Soejima, K., Arai, E., Hamamoto, J., Yasuda, H., Arai, D., Ishioka, K., Ohgino, K., Naoki, K., Kohno, T., Tsuta, K., Watanabe, S., Kanai, Y., and Betsuyaku, T. (2015). Prognostic implication of PTPRH hypomethylation in non-small cell lung cancer. Oncol Rep 34, 1137-1145.

Seo, Y., Matozaki, T., Tsuda, M., Hayashi, Y., Itoh, H., and Kasuga, M. (1997). Overexpression of SAP-1, a transmembrane-type protein tyrosine phosphatase, in human colorectal cancers. Biochem Biophys Res Commun 231, 705-711.

Takada, T., Noguchi, T., Inagaki, K., Hosooka, T., Fukunaga, K., Yamao, T., Ogawa, W., Matozaki, T., and Kasuga, M. (2002). Induction of apoptosis by stomach cancer-associated protein-tyrosine phosphatase-1. J Biol Chem 277, 34359-34366.

Tonks, N.K. (2006). Protein tyrosine phosphatases: from genes, to function, to disease. Nat Rev Mol Cell Biol 7, 833-846.

Xu, Y., and Fisher, G.J. (2012). Receptor type protein tyrosine phosphatases (RPTPs) - roles in signal transduction and human disease. $J$ Cell Commun Signal 6, 125-138.

Zhang, Y., Roos, M., Himburg, H., Termini, C.M., Quarmyne, M., Li, M., Zhao, L., Kan, J., Fang, T., Yan, X., Pohl, K., Diers, E., Jin Gim, H., Damoiseaux, R., Whitelegge, J., et al. (2019). PTPб inhibitors promote hematopoietic stem cell regeneration. Nat Commun 10, 3667.

Zhang, Z.Y. (2017). Drugging the undruggable: therapeutic potential of targeting protein tyrosine phosphatases. Acc Chem Res 50, 122-129. 